\title{
Lonely planet is OK, but why lonely physician?
}

\section{Om Prakash Yadava ${ }^{1}$}

Published online: 28 August 2019

(C) Indian Association of Cardiovascular-Thoracic Surgeons 2019

Physician burn out is a well-accepted reality, yet, an underreported and under-actioned problem facing the medical community. The traditional human-centric and touch-based practice of medicine, where most illnesses are diagnosed by either clinical inspection, physical palpation or auscultation, has now given way to technology-based imaging modalities, which require very little patient interaction. Infact, most investigations today are being done in an automated mode, overlooked by technicians and reported at the back office located remotely, for example in Asia for North America. These 'Non Face-to-Face' encounters, as against the 'Face-to-Face' encounters of yesteryears, seem to be contributing in a large measure to the isolation and physical and mental loneliness of the physicians. Though all this seems intuitive, it is just the first time that Kulkarni et al. [1] have looked at this matter in more details, including the drivers of physician loneliness and the opportunities that exist for meaningfully ameliorating them.

The contemporary trends of practice of medicine, based on internet- and telephone-based applications, show that doctors spend more time on computers than on actual patients. Even repeatedly navigating through the electronic medical records contributes significantly to the physician loneliness. This loneliness does not just impact the individual, but also his family and his patients, as his throughput is reduced and whatever he does is prone to errors of omission and commission unwittingly. Thus, though technological advances have brought in numerous benefits, we must also appreciate the downside of unabated use of these technologies. According to Dr. Kulkarni [1], technology is 'a symptom rather than a disease for loneliness in the physician'.

We are healers and intuitively, we should be able to pick up loneliness, at least in our own-self. However, reality is far

Om Prakash Yadava

op_yadava@yahoo.com

1 National Heart Institute, New Delhi, India from truth and most of this loneliness exhibits in a very subtle fashion, which may be noticed by peers and colleagues, even before the individual himself notices. It therefore behoves us that we interact with our colleagues, as much as possible, and be acutely aware and sensitized of this relatively new phenomenon with a view to identifying colleagues needing help. It is imperative for the doctors themselves, the administrators and the corporate honchos, who control the delivery of health care, to actually create and make occasions for non-work-related doctor interactions. It would thus be very interesting to have like-minded people creating groups to have musical evenings, or trekking, or going for theatre or a movie, where they can interact and de-stress. Small interventions like having lunch in a common room, or putting up a small gymnasium, or a reading room, may be a table tennis table, can also give an opportunity for the physicians to be together and have a more meaningful and purposive dialogue, other than the didacted.

We must encourage the doctors to talk about the subject of burnout and depression, for its only when we talk that we realize the extent of the problem, besides the fact that it can be therapeutic. To walk the talk, a measure we have introduced at the National Heart Institute is to organize Heart Camps in the remote Kumaon Himalayas, where the doctors can go with their families and thus serve the dual purpose of serving the community through camps and yet having quality family time, relaxing and enjoying the bountiful nature. Therefore, besides self-directed individual efforts, it will require a collective approach, infact a systemic one, to address this relatively unrecognized malady with modern healthcare - called loneliness.

No one-stop solution can be recommended and though the problem is global, the solution has to be local, indigenised and customized to the circumstances of that individual, the institution and the society around him. But one thing remains the common denominator-Connect, Connect, Connect with the nature, with the flora and fauna around and with the fellow human beings. That possibly is the surest, safest and the most cost-effective method of tackling this menacing issue of loneliness in physicians. And the add-on measure is to identify a 
meaning to life and a purpose, which would always hold one in good stead in moments of despair.

Some may call me verbose and these, loud words. But trust me, folks, that's the only way forwards!

\section{Reference}

1. Kulkarni A. Navigating loneliness in the era of virtual care. N Engl J Med. 2019;380:307-9.

Publisher's note Springer Nature remains neutral with regard to jurisdictional claims in published maps and institutional affiliations. 